Review

\title{
How Open Is the Maker Movement? Integrative Literature Review of the Openness Practices in the Global Maker Movement
}

\author{
Hanna Saari ${ }^{1, *}$, Maria Åkerman ${ }^{1}$, Barbara Kieslinger ${ }^{2}\left(\mathbb{D}\right.$, Jouko Myllyoja ${ }^{1}$ and Regina Sipos ${ }^{3}(\mathbb{D}$ \\ 1 VTT Technical Research Centre of Finland, 02044 Espoo, Finland; maria.akerman@vtt.fi (M.Å.); \\ jouko.myllyoja@vtt.fi (J.M.) \\ 2 Centre for Social Innovation, 1150 Vienna, Austria; kieslinger@zsi.at \\ 3 Institute of Vocational Education and Work Studies, Technical University of Berlin, 10623 Berlin, Germany; \\ sipos@tu-berlin.de \\ * Correspondence: hanna.saari@vtt.fi
}

Citation: Saari, H.; Åkerman, M.; Kieslinger, B.; Myllyoja, J.; Sipos, R. How Open Is the Maker Movement? Integrative Literature Review of the Openness Practices in the Global Maker Movement. Sustainability 2021, 13, 13559. https://doi.org/10.3390/ su132413559

Academic Editor: Kylie Peppler

Received: 30 October 2021

Accepted: 4 December 2021

Published: 8 December 2021

Publisher's Note: MDPI stays neutral with regard to jurisdictional claims in published maps and institutional affiliations.

Copyright: (c) 2021 by the authors. Licensee MDPI, Basel, Switzerland. This article is an open access article distributed under the terms and conditions of the Creative Commons Attribution (CC BY) license (https:// creativecommons.org/licenses/by/ $4.0 /)$.

\begin{abstract}
This article explores the multiple meanings of the concept of openness in the global maker movement. Openness is viewed as one of the key principles of the maker movement. As the global maker movement is a bricolage of diverse and situated practices and traditions, there are also many different interpretations and ways of practicing openness. We have explored this diversity with an integrative literature review, relying on the Web of Science ${ }^{\mathrm{TM}}$ database. We identified three interrelated but also, in part, mutually contested approaches to openness. Firstly, openness often refers to applying open hardware. Secondly, it is in many cases related to the inclusion and empowerment of various groups in making. Thirdly, openness appears to be seen as a means to pursue economic growth through increasing innovation activity and entrepreneurship. Our results also highlight the substantial barriers encountered by makers while aiming to open up their practices. These barriers include: value conflicts in which openness is overridden by other important values; exclusion of lower income groups from making due to a lack of resources; and difficulties in maintaining long-term activities. The different meanings of openness together with the barriers create tensions within the maker movement while implementing openness. We propose that engaging in a reflexive futures dialogue on the consequences of these tensions can enhance the maker movement to become more open, inclusive and resilient.
\end{abstract}

Keywords: maker movement; openness; critical making; open hardware; inclusion; tensions

\section{Introduction}

Today, we are witnessing a growing professionalisation of the maker-driven open hardware movement that is comparable to open-source software, which has already become mainstream. An often-claimed characteristic of the maker movement is its strong commitment towards openness. Makers are keen to realise openness as much as possible and openness and sharing seem to be key principles that makers abide by according to Millard et al. [1]. Openness is practiced by the sharing of ideas and designs locally in makerspaces, and by learning online in the wider community using multiple platforms for uploading designs and projects for other makers to use and adapt. Openness is one of the major ways in which the maker movement challenges currently prevalent production systems that rely on closed systems and intellectual property rights. Without open practices the maker movement would not be able to spread in the way we see it spreading currently.

Even though openness is such a central value to the maker movement and has such a profound role in shaping the movement's future, a comprehensive review of the topic has been lacking so far. When openness of the maker movement has been studied, the perspective has usually focused on one of the aspects of openness, such as inclusiveness 
of certain groups of people (e.g., [2]), openness of knowledge sharing (e.g., [3]), implications of open hardware (e.g., [4]) or the economic implications of open maker practices (e.g., [5]). In this article, all these different perspectives are brought together. We aim to build a comprehensive framework for understanding the multiple views on openness in the maker movement. Our key research questions are: (a) What kinds of meanings are given to openness in maker movement studies? (b) What societal goals are connected to different interpretations of openness? (c) What kinds of tensions arise from these different understandings within the maker movement?

Next, we will briefly introduce the maker movement and relate it to the starting point of this article, the Critical Making project. Then we present our review methodology. In the main body of our literature review, which is based on the Web of Science ${ }^{\mathrm{TM}}$ dataset, we will elaborate on the different meanings of openness found within the maker movement as well as the barriers encountered when opening up the practices. In Section 4, we discuss our conceptualisation of these differences as tensions and hope to show how the tensions can be lived with rather than solved. We argue that this kind of reflexive and critical futures dialogue can pave a way towards a more plural, open and context-sensitive maker movement.

\subsection{Maker Movement}

When conducting research on the maker movement, it is important to note that we are not faced with a uniform activity that follows one central blueprint and that should be reproduced anywhere in the world exactly as prescribed. Following Ong and Collier's definition, the maker movement is rather a "global assemblage" (Ong and Collier 2004 in [6]) of hacker- and makerspaces, spaces of collaborative design and grassroots innovation, brought to life by offline and online communities that make use of the tools found in these spaces. Examining their diversity and situatedness [7] in local sociopolitical realities can help extend and redefine what constitutes making and shed light on (hyper)local societal questions. But the lack of uniformity also makes research complicated. Innovative activities of groups of people are often carried out "beneath the radar" of academia and industry [8].

The current definitions of what constitutes a maker are thus wide-ranging and accommodate many practices around the common denominator of people being creators of physical objects. Many experts also attribute certain values to makerspaces, such as social responsibility, emancipation, inclusiveness, or openness (e.g., [8]). However, it has been claimed that mainstream maker practices are not always very inclusive or open. One of the best-known maker media outlets, the American magazine entitled MAKE: (https:/ / make.co/ (accessed on 7 December 2021)), has often been criticised for representing making as a hobby for privileged white males. Critics have also accused the magazine of guiding makers towards ready instructions and kits, steering them away from creative, critical tinkering and hardware hacking [9]. Concerns that the maker movement is "forgetting open hardware" were expressed when the MakerBot, "the darling of the Open-Source Hardware movement", became closed-sourced [10]. These critiques already highlight the varying understandings of openness: It refers to open-source hardware, but also to creative mindsets and openness to new ideas and innovations.

It is thus obvious that, as making itself, openness is also a multifaceted concept carrying different meanings in different contexts. There isn't any one definition of openness that could catch all the meanings attached to the term in the maker movement. Instead, there are many co-existing understandings of what being open means [11]. Openness is not a binary concept either, but there are different degrees of openness and different ways of promoting openness. Following on from this, despite the centrality of the idea of openness in the maker movement, there is no standard for what it means to be open. The understanding of openness as an evolving concept guides the work presented in this paper. This concept originally triggered the authors to explore different interpretations of openness as well as the underlying assumptions behind these interpretations and related societal goals. While interconnected, these partially contested understandings and interpretations 
of openness are guiding making practices in slightly different directions and towards different futures.

There are many, often contradictory imaginaries of the future the maker movement could bring about (see, e.g., [12] vs. [13]). Openness, however, plays a central role in shaping the movement, whatever direction it will take. Bringing about the next industrial revolution [14] requires a great deal of open practices from sharing spaces, designs and knowledge to opening up the closed "black boxes" (see, e.g., [15]) of technology. Similarly, building more maker-based businesses and economic growth in the current capitalist system requires constant balancing between open sharing and individualistic profit-making [3]. To be able to build a desirable future for the maker movement, more understanding of the implications of promoting openness is needed. This paper highlights the importance of recognising the different discourses. We argue that balancing between the different forces of openness is vital to the future of the maker movement.

\subsection{Starting Point of the Inquiry: Critical Making}

The starting point of this article is in the Critical Making project that a group of researchers, including the authors of this article, launched at the beginning of 2021. The project aims at increasing the reflexivity and criticality of the maker movement. Openness is recognised as a central theme in this quest, therefore openness is one of the focal points of the project.

In this paper, we are investigating the concept of openness from the viewpoint of critical making. Broadly speaking, critical making is understood as practices that combine making and critical thinking. For Matt Ratto, who originally coined the term, a critical approach to making highlights the thought process behind making, using the objects that are being made as reflection points [16]. While openness has not been explicitly discussed in the discourse, it is central to this understanding, as sharing thoughts and reflecting on practices together is at the very core of making as a critical practice. In the term's further development by Hertz, "critical making" serves to engage critically with technology and shows that building electronic objects can be an effective form of social argument or political protest $[17,18]$. The artefacts emerging from this process are documented openly.

The Critical Making consortium has also defined its own working definition of critical making. This working definition highlights the two parts that together form critical making: making and criticality. Criticality is defined as having multiple important aspects: locality, social responsibility, critical thoughts, impact and meaningfulness (see https:/ / criticalmaking.eu / for more information (accessed on 7 December 2021)). While the working definition was being developed, the topic of openness raised multiple questions, such as: How much openness can the consortium call for? Should an open-source license be required? Do maker communities have to actively distribute their blueprints to make these truly open and accessible? What is openness in countries where IP rights are so different from the Western setting? Some of these questions are rooted in a 2019 workshop, which was organised by prospective consortium members at the 9th International Conference on Communities \& Technologies, mainly with practitioners from the Global South. The aim was to better understand whether the term "critical making" resonated with grassroots practitioners and how they understood it. During this workshop, opensource innovation, commons and impact-driven innovation through making were central thoughts as a mechanism to become more self-sustaining through breaking the cycle of reliance on external funding. The participants expressed the need to invent new (business) models for commons-based organisations, so that these can become financially sustainable while sharing concepts, and in this process, decolonising knowledge. They exclaimed: "we have to overcome the idea of ownership of ideas!" [19].

Critical making often also tries to engage diverse groups, and individuals from different cultural backgrounds, minorities and marginalised groups. This is further discussed in the literature review, but at this time it is important to note that openness in critical making is more than sharing designs. Openness is also openness of the practice of mak- 
ing itself. Opening up the practice of making can mean inclusion of different cultural understandings of making and widening the viewpoint from that of Western, white and privileged makers [20]. According to our understanding of openness within the Critical Making consortium, opening up the practice of making has to go further than being open to everyone on paper; it also has to make it possible and feasible for all aspiring makers to truly join the practice. This may include the overcoming of unequal power relations or the offering of different scheduling possibilities for mothers or people with disabilities, for example [11]. Thus, social justice and equality can be examples of the values that are reflected in critical making practices [9] and as we will see further below in the presentation of results and discussion, empowerment and inclusiveness are some of the central concepts for openness in making or, rather, in critical making.

\section{Methodology: Integrative Literature Review}

To gain a comprehensive understanding of how openness is understood and discussed in the maker movement, we have conducted a qualitative, integrative literature review [21] of scientific studies on making. The integrative review serves the purpose of collecting and combining the different approaches to openness particularly well in a dynamically developing field of grassroots innovation studies and social movement studies, which draw from different disciplinary backgrounds.

The review protocol had three stages: (1) the planning stage, when we formulated the guiding research questions that define the boundaries of the literature to be reviewed; (2) the conducting stage, involving data extraction and coding, followed by data analysis and synthesis; and (3) the reporting stage, focusing on answering the research questions [21,22].

In conducting the literature review, we used the Web of Science ${ }^{\mathrm{TM}}$ database as the primary data source. The Web of Science ${ }^{\mathrm{TM}}$ is a publisher-independent global citation database and a platform that allows the tracking of ideas across disciplines from almost 1.9 billion cited references based on over 171 million records [23].

The research objective guiding the search was to gain a deep and diverse understanding of how openness is conceptualised in the maker movement. The diversity of the movement was a recognised starting point. From this understanding, different research traditions and terminologies were approached through different search inquiries. The questions guiding the search and analysis were formulated as follows: How is openness understood in the maker movement? What practices support or hinder openness in the maker movement?

The search queries were formulated as: "critical making", "critical making" AND openness, "maker movement" AND openness, DIY AND openness, openness AND RRI. The first search queries were discussed between the authors of this article. As the search continued, new terms were established based on the evolving understanding of interconnections and terminologies used in different disciplinary contexts. The use of different queries aimed at achieving a rich and comprehensive understanding of the phenomena being studied. An important indicator in justifying whether there was a need to broaden the queries further was the emergence of the same articles in different inquiries. This kind of saturation of collected article data during the course of inquiries meant that in practice, the emergence of new articles decreased as the inquiry went further.

Table 1 shows the inquiries that led to the extraction of articles. The inquiries are presented in the order in which they were conducted. In addition to the search inquiries presented here, some inquiries did not result in any new extractions and are thus not listed here. In addition, a few inquiries were excluded as they resulted in too many search results. In these cases the search was refocused more precisely onto the topic of interest by modifying the inquiry. As the search continued, more and more overlap was observed, which can be seen from the lower number of new extracts from later inquiries. 
Table 1. Search inquiries in the Web of Science ${ }^{\mathrm{TM}}$.

\begin{tabular}{lcc}
\hline \multicolumn{1}{c}{ Inquiry } & Results & Extracts \\
\hline "critical making" & 56 & 28 \\
"maker culture" AND openness & 7 & 7 \\
"maker culture" AND open & 27 & 19 \\
"maker movement" AND open & 62 & 35 \\
DIY AND openness & 10 & 7 \\
do-it-together AND maker & 3 & 3 \\
hackerspace AND openness & 3 & 1 \\
makerspace AND openness & 11 & 7 \\
makerspace AND open & 53 & 32 \\
makerspace AND inclus * & 13 & 9 \\
"fab lab" AND open & 23 & 15 \\
"open hardware" AND maker & 12 & 4 \\
hackerspace & 25 & 8 \\
"open hardware" AND RRI & 1 & 1 \\
"maker movement" AND business & 26 & 13 \\
"hacker movement" & 4 & 2 \\
"open innovation" AND grass-root & 5 & 5 \\
"maker movement" AND community & 56 & 37 \\
Total articles extracted & 96 & 233 \\
\hline
\end{tabular}

The selection of articles for an in-depth qualitative analysis was initially done by the first author, followed by a discussion about the selection amongst the co-authors and one additional researcher from the Critical Making consortium. This expert was specifically consulted for uncertain cases. First, the title of the article was reviewed. If a title did not provide enough information, then the abstract was also read through, after which the selection was made. The main criterion for the selection of articles was their focus on openness of the maker movement. Both peer-reviewed and non-peer-reviewed articles were included. These included some conference papers, theoretical articles as well as empirical research. A broad picture of how openness is conceptualised was the goal of the selection. All types of maker practices, excluding purely educational makerspaces, were included. Only articles published in English were considered, however. This might limit the extent to which indigenous making practices of different cultures are represented, for example. There might also otherwise be some overrepresentation of European and North American perspectives, even though the global maker movement has been captured. The publishing year of the articles was not a selection criterion, but all selected articles were published in or after 2012.

The initial inquiry process resulted in a total of 233 potential articles. From these, 40 were selected for in-depth analysis based on the centrality of openness in their contents. As in the earlier stage, the form of the articles selected was left open, and a broad picture of the phenomena was sought. Available information of these articles was extracted from the Web of Science ${ }^{\mathrm{TM}}$ to Zotero software, which enabled the establishing of a bibliography for the selected articles. This bibliography has been added to the public Zotero library of Critical Making and can be accessed openly (see https: / / criticalmaking.eu/resources / (accessed on 7 December 2021)).

The qualitative in-depth analysis was based on careful reading of the articles and the thematic coding of contents in table format. In this phase, the definition of openness was intentionally left open and different definitions in different articles were embraced. The table included themes such as "definition of openness", "barriers to openness", " goals" and "solutions/results" that were recognised as important in understanding the complexities of how openness was conceptualised. After the first round of thematisation, the analysis proceeded with more detailed categorisations within the themes. Subcategories were created on the basis of wordings and metaphors that were used in describing the meaning of openness and its barriers. In addition, we coded the different activities that were connected to openness. The analysis process indicated that there are three substantially different ways 
to understand openness in making. The first author of this article mainly conducted the analysis, but the results were regularly discussed and tested between the three researchers responsible for data analysis (H.S., J.M. \& M.Å.) by cross-reading selected articles. Based on these discussions, the categorisation scheme was jointly elaborated throughout the process of analysis. Finally, the results were validated with the two members of the Critical Making research team (B.K \& R.S.) who have particular expertise in maker movement practices and critical making.

\section{Results}

\subsection{Different Interpretations of Openness in Making}

Our results show that there are three different ways to understand the meaning of openness in the maker movement and maker space literature. The first places emphasis on open hardware and has its roots in the open hardware movement. The second connects openness to social inclusiveness. The third sees openness as a means to promote entrepreneurship and a new type of economic growth. These understandings are, in part, mutually contested and connected to different societal goals and therefore, in some cases, they are difficult to pursue simultaneously. In the following, we introduce in greater detail the three interpretations of openness and the underlying assumptions behind them. After that, we will move on to identify the barriers arising from the different approaches and their consequences for making.

\subsubsection{Open Hardware}

The open hardware concept has its background in the open software movement, which has had some major effects on the way technology and software are used and employed in business. Attempts have been made to adapt influential open software ideals to produce hardware, even though there are some major differences between the two. There is no generally accepted definition of open hardware, but it usually refers to hardware with open interface, design and production tools, so that it can be replicated and further modified [24]. The open hardware movement is an important starting point of the maker movement, as open hardware designs are some of the main tools of most makers. In branded FabLabs, the Fab Charter also explicitly states that every FabLab commits to the open sharing of hardware designs [25].

Currently, open software and hardware go hand in hand in the maker movement. The openness of hardware and software are usually seen as merely different sides of sharing designs [26]. Open software is a central tool for makers, allowing them to control the physical machines they use [27]. In addition to software and hardware, sharing data openly is also part of the same value system.

Openness of hardware designs is often seen as having intrinsic value in the maker movement $[28,29]$. Open hardware designs can be a source of customisability and endless creativity, encouraging others to further modify and adapt hardware to suit their purposes or creative goals [30]. On the other hand, openness of hardware also has more practical meanings. For example, openness of hardware designs enables cheaper distributed production [13], customisability to suit local conditions [4], and more personalised design compared to traditional production methods [31].

One of open hardware's more obvious practical dimensions is its potential for relieving resource scarcity and increasing the availability of things. As machines, such as 3D printers, laser cutters and CNC routers, become more affordable and more widely available, the opportunities for making become more diverse. Big online platforms for sharing hardware designs (such as Thingiverse) also bring hardware designs to all aspiring makers [27]. This ideal, however, has also raised some critical voices in the maker community. Easy manufacturing devices such as 3D printers and the online platforms for sharing designs have been accused of only accelerating current overconsumption and creating more unnecessary stuff without the user necessarily even engaging in the technical design practices [32]. 
However, there are some undeniably good applications for 3D printing that can help solve some current societal problems. 3D printing is especially celebrated for its variability. It can be used to provide more customised aids for the disabled, for example. Sharing aid designs online, downloading other people's designs and customising them is relatively easy and is becoming more widely available. 3D printed aids are also often more affordable (if a little lower quality) than standard aids available through other channels [33,34]. Designing and prototyping with other maker techniques can also provide accessibility aids for more people, as cheaper, more frugal designs are being developed [35]. The ECfunded careables.org platform is a good example of open access to DIY solutions in the healthcare sector.

Many other people also benefit from increasing availability and customisability of hardware. New maker techniques can be utilised to provide more laboratory equipment for educational purposes in areas suffering from resource scarcity, for example $[4,36]$. More affordable and easier-to-build science tools can also be developed for use in developed countries by DIY science practitioners [37]. The maker movement can also provide cheaper yet high-quality maker tools [38]. In developing economies, a maker approach can also help ease the shortage of medical supplies [39].

Crises like the current COVID-19 pandemic can also create new scarcities, even in developed economies. During this global crisis many medical supplies have been in danger of running out, as demand for them has suddenly exploded. In some countries, the open hardware approach has been invaluable in providing more medical hardware, such as face masks, face shields and even 3D printed ventilators [40]. Hospitals in both developed and developing economies have bought medical hardware from makers even though it cannot be guaranteed to fulfil all safety requirements, as regularly manufactured hardware was not available [41]. Pearce presents a call for making all essential medical hardware open-source, as currently it is not possible to produce most medical hardware in makerspaces using publicly available information. Going forward, as this pandemic is probably not the last, there is significant room for improvement [42].

\subsubsection{Inclusiveness and Empowerment}

Many makers, however, go further with their demand for openness, also advocating more diversity, equity and inclusion in maker practices. This kind of thinking stems from the idea that the maker movement should above all be a social movement with a drive to make a societal impact. It is not perceived to be enough to share one's designs openly on the internet, but instead emphasis is placed on ensuring that making is possible for different groups of society, including underprivileged ones who have often been excluded from making, even if unintentionally $[5,34]$. While making has previously been dominated by heterosexual, white, middle-class males, the values of opening maker practices are now finally being recognised by the wider community [43] and the calls for more diversity and inclusion of people of other genders, ages, races and sexual orientations are undeniable [44,45]. Empowerment and inclusiveness are central concepts for openness in making. These themes raise a very important question: openness for whom? It is essential that we look more closely at this question to find out who is benefiting from openness practices in making, or who are makers being open for. One perhaps slightly easy answer to this question is "consumers" or "citizens", suggesting that it is ultimately everyone that benefits from open maker practices $[27,46]$. In this stream of literature, the maker movement is seen as empowering for the general public (as opposed to the "elite").

The empowerment of consumers or citizens can happen in many ways. On one hand, citizen science projects are trying to create a more participatory and inclusive way of making science. The idea is that science should not be only something scientists do and citizens learn about. Instead, science could and should be done in collaboration with different sectors. Empowering citizens to collaborate in creating data that is relevant to them in their everyday lives is seen as important, and the created data should then be made available in a form that is understandable and relevant to citizens, too $[47,48]$. 
On the other hand, empowering consumers can have more to do with producing physical artefacts than data. This was recognised in many instances in our literature review as empowerment to interact with and co-create the material surroundings of our everyday lives. This act of making can be a political protest and a way of influencing the surrounding society [26]. It can also be empowerment to be creative [49] and to imagine different futures, and to see oneself as a creator of the material future we are heading towards [50]. Interacting with the material world can also contribute to sustainability, as consumers learn to interact with everyday objects, such as clothes, and repair and redesign them instead of only buying, using and discarding [51]. In light of the ongoing global e-waste crisis due to the obsolescence of ubiquitous technological artefacts, industrial players should obviously produce more sustainable devices [52-54] but, until this happens, an individual user's ability to repair through applying maker knowledge is a powerful expression of agency [55] and is supported by the recently launched Right to Repair movement, while makerspaces at e-waste sites are also empowering local makers [56,57].

Some authors go even further with their imaginations and aspirations. A big systemic change can be imagined where passive consumers become active producers. With new and developing technology, consumers could potentially produce anything they need or want, but in a more customised and sustainable way than current production systems do. This shift of paradigm would encompass cultural change where producing or making becomes more important than consuming, effectively replacing the current prevailing consumer culture $[49,58]$. It would also mean a major change in current production systems, as consumers would effectively disrupt current production systems [13]. The key that unlocks this path of future production capabilities can simply be seen as unlocking the individual's creative power and realising their capacity to make [59], but many authors also emphasise the importance of making technology more widely available and achievable [13].

Inclusiveness also points towards underrepresented groups, such as women, gender diverse people, young people, ethnic minorities, and people with disabilities. Including more women and girls in making activities can be a goal in itself, pointing towards more females feeling empowered to get involved with normatively masculine subjects of electronics and coding [44]. Including children and young people can have the same goal, increasing the amount of people comfortable with technology building [46] or even explicitly increasing the share of science and technology students [60]. In developing economies, the empowerment of young people can also help tackle local challenges, such as resource scarcity [4]. Some authors also stress the importance of including people from all socioeconomic classes in maker activities, as working together with different people can be enriching for all those involved. However, current systems can encourage working in homogenic groups, and people generally have the tendency to favour others from similar socioeconomic backgrounds $[45,61]$.

Like the rest of society, making is also usually based on the presumptions of ablebodiedness and neurotypicality. Critical makers have started to express how problematic these assumptions are, as big groups of people are left out of making activities. There is a stream of literature focusing on exploring inclusive practices allowing people with disabilities to make, thus taking an active role in designing their material surroundings instead of being passive receivers of assistive technology [33,34]. Inclusive practices can lead to manufacturing and designing aids for disabled people using open hardware platforms and 3D printing technology, for example [34,35]. Blind and visually impaired people also face great challenges in participating in maker practices. The most common maker tools are based on visual cues such as colour codes, blinking lights and visual pictures, and computer programs don't always fully support screen readers. There are, however, some efforts being made in opening up maker practices to these groups by developing new software and hardware that allows 3D printing without visual computer modelling, for example [2,62].

The inclusion of disabled people in making practices is also seen as having positive impacts at both the individual and societal level. As disabled people are able to interact 
with their material surroundings, for example by 3D printing, they gain a sense of capability and empowerment [33,34]. They can also get more practical gains, such as more customised and inexpensive everyday aids [34]. Making can also be a source of creativity for disabled people [31]. Makerspaces can act as community spaces where the disabled are able to socialise and, ideally, where greater inclusion can also be achieved outside makerspace facilities [43]. Even though the empowerment of disabled people can be seen as a form of empowering underrepresented groups, these are also somewhat separate practices. Disabled people need new hardware more often than others in order to be able to join making practices. With other underrepresented groups, however, the efforts needed mostly concern reframing the narratives and contexts of making. The previous research literature also mirrors this difference, and these phenomena are mostly dealt with separately.

\subsubsection{Economic Growth and Makerspaces}

Many authors highlight the potential of the maker movement for generating economic growth [46] and creating opportunities for entrepreneurship. Makerspaces can offer possibilities for ideation and innovation together with other creative tinkerers. Makerspace tools also enable prototyping with a low budget, and can be a stepping stone towards securing venture capital, scaling up and creating a successful business, for example [12]. While the hope for the maker movement's economic impacts is a common one, this aspect is somewhat contradictory with the imaginations of a new economic paradigm, as here the emphasis is not on changing the system but finding growth within the current system. Despite this contradiction, the maker movement is on many occasions celebrated as a potential source of economic gain $[12,46]$, which emphasises the divisions found within the maker movement.

The role of makerspaces can be constructed as an accelerator of learning for business and entrepreneurship [5]. At the same time, the maker movement attracts individuals into product design and, through that, launches more "accidental" entrepreneurship [12]. In terms of increasing equality, the maker movement also increases female inclusion in starting new businesses [49]. Ryana \& Striukova [60] observe that individuals carrying out innovation are likely to be significantly different compared to innovation activities of firms. There, we may differentiate social innovation from business innovation. An open, social innovation is more diffuse, and it may take many different forms and be located in variable contexts. This is different compared to business-driven firms, where innovations are more accurately defined and visible. Similarly, Langley et al. [29] separate socially driven forms of organisation from commercial operators by seeing differences in their social motivation, collaboration forms, openness and working practices.

Regarding maker technologies, Langley et al. construct technology as an enabler for entrepreneurial opportunities and emerging business models. Their findings suggest that, at least in some contexts, makers could benefit from designing new solutions for wider audiences by increasing multiperspectivity in development [29]. Prototyping relates closely to technological improvements. There, the maker movement can contribute to lowering the costs of technological development and, through that, attracting funding and creating sales [12].

Makerspaces themselves are diverse in function and purpose, and there are makerspaces that specifically aim at fostering entrepreneurs. These makerspaces create meeting points for entrepreneurs in different phases of their careers and with different goals. Fostering an entrepreneurial community can be beneficial, especially for the entrepreneurs involved but also for the wider local economy, as new and accelerating businesses boost economic activities in the area $[5,63]$. On the other hand, it may very well be that in some making cultures monetary aspects are less prominent. There, making may rather be about self-transformation, or a hobby (see [59]). In these circumstances, making can be seen as a potential path towards professional development, business conceptualisation or entrepreneurship. It could be described as a pedagogy of making that creates favourable circumstances for different learning curves to emerge. 
Aryan et al. [28] observe that society-driven or sustainable innovation is traditionally considered a peripheral activity. Driven by financial crisis, social movements and postgrowth philosophy, for example, societal innovation has developed towards mainstream thinking and activity. Even though platform-based business models propose a threat for exploiting results without correct repayment for real idea generators and inventors, platforms have gained essential relevance as a ground for new business creation within the maker movement.

What is the relationship between maker entrepreneurs and openness, then? For one, openness and maker movement can be seen as possible tools for creating entrepreneurial opportunities [27]. Open innovation, where makers can support the innovators within companies, can also act as a booster of innovation activities and business [64]. On the other hand, there are conflicts between financial motivations and openness ideals in making. Balancing between these is sometimes understood to be a goal worth pursuing, and there are in fact business models that successfully combine open hardware ideals and financial profitability $[29,65]$.

Yet another angle to openness of making focuses on the openness of innovation processes. Open innovation is a term that refers to innovation processes that are not closed in one unit of innovating but instead use multiple sources of innovations [39]. Open innovation is seen as a framework for combining innovation in developed and developing economies [39] as well as utilising maker networks to complement the innovation processes of companies [28]. Innovation processes can be made more open through cooperation between commercial firms and maker networks, where the different understandings supplement each other. In open innovation, more diverse knowledge and skillsets are achieved, as makers and in-firm innovators often have different backgrounds and perspectives [64]. The benefits of open innovation also include the development of more frugal and relevant hardware designs as well as adaptability for different contexts and actors [39].

To look at future opportunities from combining business and the maker movement, extended memberships represent one evident direction [49]. This is close to the existing view of seeing the maker movement as a dense but diverse network that pulses with new ideas and innovative thinking [12]. In the future, makerspaces can increasingly have a function as a societal, multi-stakeholder operator and a node. There, makerspaces may increasingly offer possibilities for cooperation, where societal needs and challenges are responded to by combining wider perspectives, motivations, and scopes of learning and business.

\subsubsection{Contested Meanings of Openness in Making and Related Goals}

As described in the previous sections, the aim of pursuing openness can generate from different societal goal settings and understandings of what it ultimately means to be open. Consequently, suggested solutions for promoting openness may differ as they target different kinds of openness. Understanding this variety and the potential tensions between promoting economic growth and regeneration, for example, through open hardware business and innovation as well as through creating inclusive spaces for making, is necessary when aiming to create openness tools for the maker movement. To clarify the different roots of the definitions of openness identified in the literature, we have collected an overview of the discussions described in the previous sections in Figure 1.

In the next sections, we will elaborate how the different barriers to openness have been identified in the literature and what kinds of solutions have been suggested to overcome these barriers. The overview presented in Figure 1 also illustrates the variety of ways in which different barriers are addressed and emphasised in different articles. 


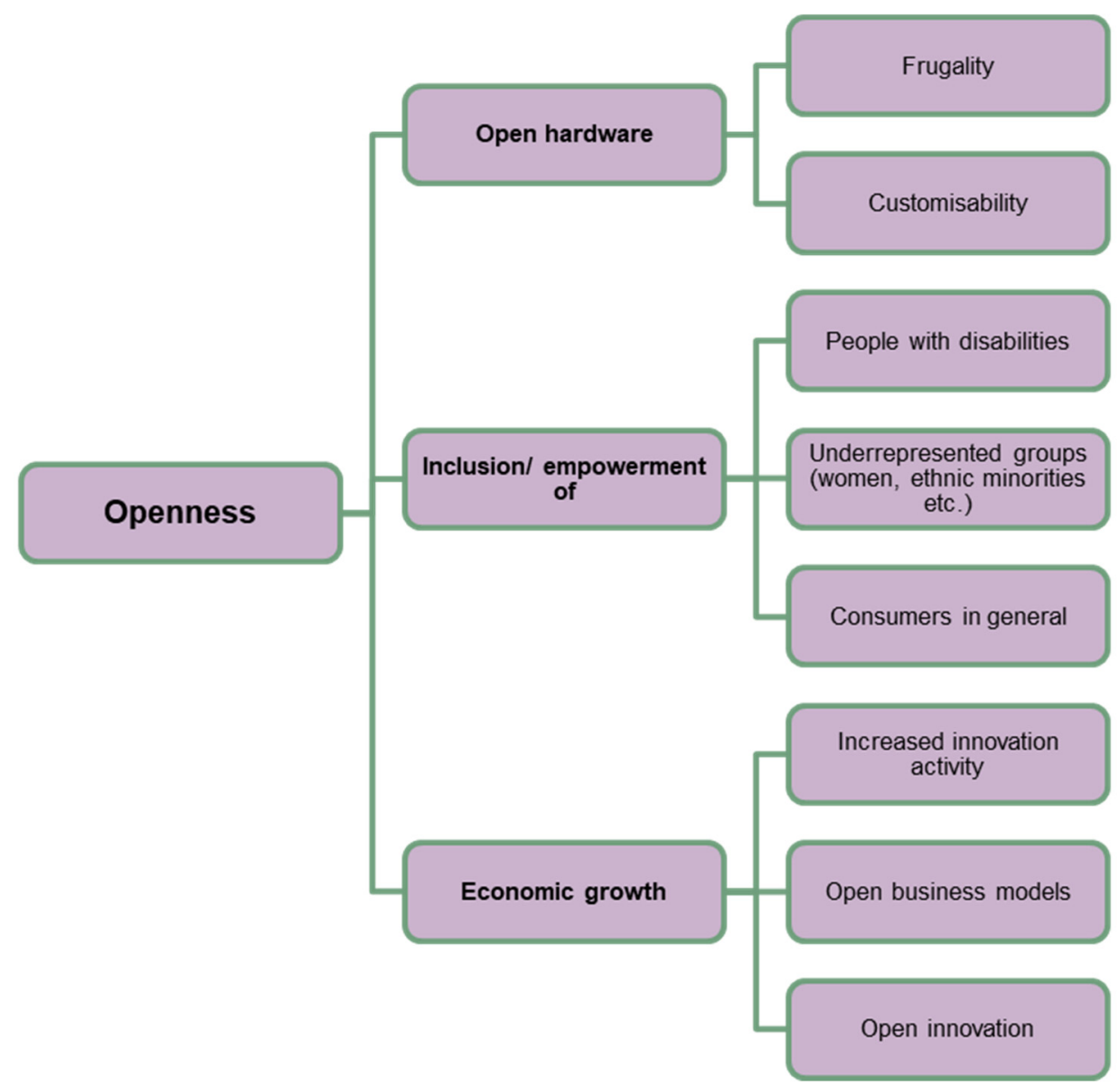

Figure 1. Different meanings of openness and related societal goals.

\subsection{Barriers for Openness in Making}

Even though openness is a central ideal in the maker movement, there are several barriers to being fully open and inclusive. This can be exemplified by the rather homogenous participants found in most maker activities, which are comprised in large parts of white, middle-class males [44]. Mechanisms of exclusion are mostly subtle and unintended [61], which often makes them hard to recognise and correct. Luckily, there is a growing understanding of these issues and there are many solutions recognised in the literature review. These dynamics are considered in this chapter.

\subsubsection{Value Conflicts-Openness and Individual Gains}

One commonly recognised barrier for open practices in the maker movement is value conflicts. Even when openness is ideologically important to makers, it often conflicts with other values such as financial motivations [36] or other individual aspirations [3]. These conflicts might lead to not sharing one's laboured designs freely for others to copy [65] or patenting one's innovations despite the commonly held value of open sharing [3]. In part, these conflicts stem from the fact that making always costs something, as materials are not free, and in other instances makers are not aware of the different licences that exist for open-source hardware and what the consequences of their usage is. This is also where the open hardware movement differs from the open software movement, which it borrowed many of its values from [66].

Langley et al. present the dilemma between openness and economic profit as a choice that every aspiring maker entrepreneur needs to make at some point. They see open sharing and commercialisation as contesting logics that need to fit together somehow, for example by choosing (mainly) one over the other. Moving to conditional sharing -where, for example, a membership fee is a condition for sharing anything - is another option for 
merging the two approaches [29]. On the other hand, Troxler and Wolf [65] have found examples of functioning enterprises with open business models, where 3D printing and consulting, for example, comprise the profit, and no licensing or only creative commons licensing is needed. In these cases, the entrepreneur's own morals and sense of fairness can be central, as there are no established rules for practicing a fully open-source business. For example, vendors of 3D printed objects can share their profits with original designers who have shared their designs openly on the internet, but this is entirely up to them as there are no legal requirements or even community standards for doing this kind of business [65]. Similarly, Ferreira [67] has mapped various types of functioning business models with openness of hardware designs, concluding that profiting from open-source hardware financially is possible in many distinct ways.

Individualism can pose challenges other than economic profit generation. Collaborating on a project is not always as simple as one would hope, and makerspaces can become places for individual projects where the sense of community often mentioned when describing the maker movement might not manifest into reality [3]. It seems that makers in many cases end up working in relative isolation, as every person might have their own goals, interests and projects $[3,5]$. Sharing time and knowledge in the form of helping others is also not always seen as desirable, as individuals might perceive these resources as too valuable for free sharing [3]. This is especially prominent when the skills in question are professional and could also be used to make money [61]. When makerspaces try to include different types of makers there can also be difficulties in sharing the space's resources in a fair and just way. For example, entrepreneurial makers may be seen to be using too many resources compared to their peers as they are accelerating their own business in a shared space of time [63]. One solution to this is limiting the time and storage space available to any one member of a makerspace, even if this limits entrepreneurial opportunities [49].

Conscious efforts of community creation were discussed in the literature as a tool for creating more openness in makerspaces [5]. A maker's sense of community can be consciously advanced in the hope of leading to more willingness to share. Creating a diverse community was also perceived as a tool for advancing entrepreneurial making, as it allows aspiring entrepreneurs to get the support of others with similar interests but different skillsets [12]. Creating an active community can also help to create more continuity of making practices [30]. Online platforms are also a prominent and effective tool connecting makers over even large spatial distances and allowing the sharing of designs and ideas globally $[27,29]$. Making can also act as a setting for creating meeting points. Maker activities can bring together scientists and citizens in citizen science projects [47], or offer a common discussion platform for solving local societal problems [26]. Bringing together people from different socioeconomic backgrounds in making or hacking can also be beneficial and lead to greater inclusion of people from low socioeconomic classes to society [45].

\subsubsection{Structural Barriers: Privileged Making Practices}

Despite making usually being described as an activity open to all who are interested in DIY (do-it-yourself) practices [49,60], there are several structural barriers that exclude certain societal groups from making activities. In this chapter we consider the privileged presuppositions often found in the maker movement excluding lower socioeconomic classes as well as other marginalised groups. As mentioned above, the maker movement contains mostly white, middle-class males, and there are several structural barriers that explain a big part of why this is so.

Firstly, the costs of making can exclude some people, be they material and prototyping costs [35] or membership fees of makerspaces [28]. The excluding impact of costliness can also extend to establishing [34] and sustaining [60] makerspaces and securing the best and most suitable environment for pleasant and inclusive making experiences [43]. On the other hand, providing wider access to makerspace tools is a common motivation behind establishing makerspaces [5,38]. Some makerspaces even offer free access [5]. Other 
techniques of lowering costs of making include using cheaper materials [38,47], creating new, more affordable maker technologies $[13,27]$ and diversifying a makerspace's income stream to take some pressure off membership fees [49]. Government and institutional initiatives in several countries aim at increasing interest in STEM education among young people by financing the establishment of makerspaces that host free educational activities for children and young people [60]. In Germany, makers even recognised basic income as a possible means for focusing on open hardware innovation [28].

Even with openness-minded makerspaces, economic capital can be a factor that directly shuts some people out. Free access to spaces and tools can be central for some makers [3], especially when considering children and students [60]. However, most makerspaces collect a membership fee of some amount in order to be able to function [3]. Some makerspaces want to encourage joining with low or even nominal membership fees, while others have rather high membership fees [28]. Even rather high fees can be justified by comparing the membership fee to the cost of buying all the machinery individually, which is usually even more expensive and thus even more exclusive [49]. In this way, makerspaces can make the tools accessible for more people, even if not everyone.

The idea of making as a pleasurable hobby can also be exclusionary since not everyone can afford or have the free time necessary to make just for fun [13]. Makerspaces can however have an atmosphere that does not support making for practical purposes, and creative and fun forms of making are strongly preferred [61], at least in economically developed countries. In developing countries making can have a different meaning, however, and local needs can be met with a more practical makerspace approach $[4,26,68]$.

In many parts of the world, resource scarcity can be a big issue that complicates or even prevents maker activities [4]. The materials that Western makers use routinely and are able to purchase from any hardware store might not be available elsewhere [68]. The current COVID-19 pandemic has given even relatively well-developed countries an experience of suffering from resource scarcity, as medical hardware has been in danger of running out [40-42]. Luckily, with some resourcefulness and creativity, alternative, frugal designs utilising locally available materials can be developed $[41,42,68]$. This, however, requires a certain degree of education or experience in making.

The privileged Western maker culture mostly discussed in the research literature also stands in opposition to many older concepts of DIY or repair culture that have developed outside the Global North. Examples of these practices are the Brazilian gambiarra and Indian jugaad, both of which focus on repairing broken things and dealing with resource scarcities in a creative way. These concepts are more deeply rooted in these societies and cultures than newer maker culture. They are also more practical in their approach, solving relevant societal problems [32]. In their similarities and differences with the mainstream maker approach, these indigenous concepts highlight the long history of DIY that goes way further back than the invention of 3D printers and do not necessarily require expensive lab equipment.

\subsubsection{Cultural Barriers in Maker Practices}

In the previous section, we highlighted some structural barriers to openness in making. In addition to these, there are also other, more culturally derived sources of exclusion. Even though these are intertwined in many ways, there is a need to discuss them separately to gain a clearer analytical understanding of the diverse dynamics of exclusion.

Not all makerspaces are able to create a model and host activities that would create interest and relevance to larger groups of people. This can lead to low participation rates and alienation of the majority of local communities from makerspaces, as they develop a feeling that a makerspace is not easily approachable [69]. Sometimes making activities might simply be uninteresting to the majority of people [51] or feel too intimidating, for example because of the high technology used [69]. Certain groups might also be more vulnerable to alienation, for example because of language issues making it more difficult to interact with other makers [43,44]. Some researchers claim that even cultural 
understandings of making might be a source of alienation, and that including wider understanding of "making" beyond the current technology-focused understanding could be beneficial [70].

These challenges point towards the need for defining specific target groups that a makerspace wishes to reach. Different target groups call for different activities (see e.g., [46]), and there are in fact examples of makerspaces that successfully specialise for certain target groups. One such example is Men's Shed, a makerspace chain for older men that is designed to support their mental health and offer a community around woodworking [43]. Many makerspaces also wish to engage children in their activities. In these efforts, it is important to depart from their interests instead of the infrastructures of the makerspace in order to spark a genuine and long-term interest in making [69]. Offering enough support and appropriate explanations is also important when hoping to engage young girls, for example [44]. Departing from local problems and providing relevant and easy-to-use opportunities of using data are also good tools in citizen science projects, where wider communities are called in to making science with scientists [26,47].

Other, more subtle barriers to the openness of makerspaces include high cultural and social capital needed to (comfortably) work in these spaces. This can mean having higher education or simply having learnt the correct ways of interacting and behaving to match the high-class atmosphere prevailing in some makerspaces [49]. People generally have a tendency to favour others who are similar to them, and this extends also to the maker movement, where having high cultural and social capital can be very beneficial or even necessary [61]. Furthermore, making and especially successfully becoming a maker entrepreneur often requires prior (higher) education [59] and/or family that is able to financially support the maker's activities [27] or extensive social networks [60]. As makers are usually from higher societal positions, the system also has a tendency to reproduce itself. New makers are often recruited from the social networks of current makers and, for this reason, they tend to be in similar societal positions $[27,43]$. Skills and knowledge are also often needed to get started with making, which inevitably excludes some people $[37,38]$.

Several efforts have been made to create easy entry points for making to include people with lower socioeconomic capital and less technological knowledge. These include creating easily reproducible parts that can be used to build different designs [38], organising workshops with lower entry barriers than regular activities [43] and making sure there are sufficiently easy elements in production kits offered in workshops [50]. It can also be good to ensure that people can utilise their prior knowledge in new platforms by using popular coding languages, for example [30]. New technology is also constantly becoming easier and cheaper to use, which makes digital making accessible to more people [13]. Several authors also emphasise the importance of having technological help available in a makerspace, especially when including groups like children and people with disabilities $[33,34,44]$, and publishing proper, clear and detailed instructions online for aspiring makers to use $[13,37,51]$. When looking to include different socioeconomic groups, the physical place of the makerspace plays an important role as well, and locating it in a diverse neighbourhood probably leads to a more diverse maker community [43,46].

In the literature, a lack of and need for long-term commitment in making was also identified. As many engagement activities include short-term, one-off workshops, participant long-term interest in making was not always sparked [69], or there was no good way available for them to keep up with their new hobby [33]. A quick pace of change with regard to technology in certain subcommunities of makers, such as digital musicians, was also identified as a barrier for long-term commitment [30]. In order to create sustainable communities around open hardware production, committed makers are essential. Without long-term commitment, lasting impacts are also hard to achieve.

\section{Discussion: Tensions Arising from Different Understandings of Openness}

In the previous sections, we have shown that openness in making is a multifaceted concept with many different meanings. More than a conceptual question, it is a question of 
different understandings of what the maker movement does and should look like. There are competing forces regarding many factors of openness, which leads to tensions within the maker movement regarding potential future pathways. In this section, we will have a closer look at these tensions. Drawing from the findings of critical futures studies, we claim that, rather than aiming to solve these tensions, the maker movement would benefit from engaging in critical dialogue on them to achieve understanding of their nature and to "become more aware of them and how they impact our daily lives" [71] (p. 57). Hence, we argue that the identified tensions can teach us about different perspectives for varying social realities of those engaged in making. Following this line of thinking, we will suggest the following five conversation topics for embracing the recognised tensions.

\section{Tensions between different economic stances}

The first tension considered here is between different economic stances towards making. On the one hand, making can be seen as non-commercial in nature, even criticising the prevalent capitalist system. In this line of thought, the maker movement is often seen as a way to increase financial equality. On the other hand, there is an entrepreneurial, even commercial side to the maker movement, where making appears as a way to increase innovations and boost entrepreneurship.

There are some rather obvious conflicts between these two lines of economic thought. Open sharing is very central to makers wishing to disrupt the current production systems and capitalist order. This, however, can leave their designs vulnerable to exploitation by other, more commercially minded makers. To prevent this, the conditions of "free sharing" should be discussed more clearly, and open-source patenting could also bring some relief to the problem. If the different stances are not in conflict, a fruitful co-existence of differently minded makerspaces and maker networks can flourish.

\section{Tensions arising from different societal contexts of making}

Next, we want to emphasise the tensions that arise between different contexts of making. These contexts differ in both economic and socio-cultural aspects, and the division between the Global North and Global South can be applied to characterise the difference. As seen in the literature review, in the Global North, defined by economic wealth and prosperity, making is mostly a fun hobby. In the Global South, however, making is more often about coping with resource scarcity. In the South, making also relates more often to traditional practices (such as gambiarra or jugaad) and the frugality of innovations plays a more central role.

Considering the tension of different contexts, there is not so much a direct conflict but a disconnection. The tension arising from the practice of making in such different environments can make the exchange of ideas hard, and obviously geographical distance does not make it any easier. If cooperation between different regions could be fostered, this could, however, be beneficial for both partners (see e.g., [39]). The connections between regions can be fostered both in online formats and joint projects. In this case, openness can mean both having an open mindset, that allows connecting with people from very different backgrounds, as well as concrete measures to share more ideas between different regions. At best, global maker connections might be a small way of coping with global inequalities (see e.g., [4]).

\section{Tensions between different social imaginaries of the societal role of making}

The third tension we turn our attention to concerns different imaginaries of what the future of the maker movement could look like. On the one hand, the maker movement can be imagined to bring about the next industrial revolution and, with it, radical empowerment of consumers. This imaginary often also relates to hopes of contributing to the sustainability transition taking place. On the other hand, making can be seen more as a resource for STEM education, increasing young people's interest and skills in technology. In this sense, making might not have any real radical aspects to it, but it might be seen more as a new way of supporting current systems.

Perhaps the most notable conflict between the different imaginaries comes from not realising the difference. The inclusion of making in education might be seen as something 
radical, even if the actual practice does not live up to the expectations (see e.g., [72]). This is where the critical making approach becomes central: the term makes the distinction between critical and "regular" making, highlighting the fact that not all making is in any way radical or revolutionary. Educational making can be critical, of course, but distinguishing more precisely might help avoid misconceptions. One of the other ways of combining the two approaches might be by opening the black boxes of technology [15] that allow both deeper learning and radical empowerment of consumers.

Tensions between individual versus collective orientation

The fourth tension points out the differences between individual and collective orientations. These contradictions may stem from, for instance, differences in understanding collective aims or, more fundamentally, from sharing different values. A practical example might be the previously mentioned contradiction between open sharing as a central value versus the individual aim to earn through innovation and patenting.

Collective orientation and sharing can be reinforced by supporting sharing in making, for example, such as rewarding activities that promote openness. In a more fundamental sense, managing these types of tensions is about processing collective values to better suit with individual makers and their personal values. When the community is able to communicate and reconstruct its core values in a participatory and transparent manner, it increases awareness of itself and its members simultaneously. Shared vision-building is an example of this kind of communal process, where aims and values of individuals can be reflected with organisational/community-level desires [73]. Even more important reflection between collective and individual directions occurs on a daily basis, in discussions with other members of a community. By supporting the constant, low-hierarchical discussion culture within a maker space, the organisation increases the likelihood that different opinions meet-and build on-each other.

\section{Tensions between different temporal dimensions}

Some makerspaces are characterised by a lack of long-term commitment among participants. One reason causing discontinuity relates to the punctual nature of project work. In some makerspaces the projects may not be that interconnected content-wise and they last only for a specific length of time. This kind of project reality has a tendency to cause a lot of rotation within the community. Responding to this kind of challenge may not be an easy task. Nevertheless, adapting strategic thinking in the longer-term planning of a makerspace may help to build a more structured project portfolio, allowing the development of contents and community in a more persevering way.

Another example of temporal difference relates to fundamental aims of making. It can be asked, for example, if the makerspace exists for the renewal of future society or whether it shares a more immediate orientation in contributing to the learning of makers and/or improving their well-being. For this purpose, agility and flexibility are valuable. Being able to communicate its purpose thusly, a makerspace is also likely to reduce mismatches in orientations, aims and world-views between makers, organisers and stakeholders.

\section{Conclusions: From Tensions towards Creating Reflexive, Critical and Open Futures}

As we have shown in this article, openness is a complex yet very central concept in the global maker movement. As a general conclusion, we want to emphasise that there is a need to critically reflect on the contested understandings of openness and the consequences that the related tensions may have for the future pathways of making. We also propose that engaging in a reflexive futures dialogue [71] can enhance the maker movement to become more open, inclusive and resilient.

When considering the future of the maker movement, its stances towards open practices is central and cannot be overlooked. As discussed in the previous section, there are many tensions within the movement that hold the potential for conflicts or discontinuities. To build a resilient movement that can potentially challenge current systems of consumption, production and distribution, these tensions need to be recognised and considered. More than that, the pathways chosen in relation to these tensions will have a considerable 
effect on the way the maker movement will look in the future. This is why open discussions are so vital to ensure the movement also reflects its members in the future: diverse and evolving, with a multiplicity of voices. At the same time, aiming for a consensus might not be a good strategy while, instead, a plurality of approaches should be embraced.

The literature review also pointed towards several gaps in the research as well as needs for deeper understanding. For one, there is a call for more future-oriented approaches in studying the maker movement; this could benefit the movement by supporting holistic, societal debate about the role and forms of making and about desirable and feasible futures for the maker movement. Secondly, a more concrete understanding of managing the tensions recognised in this review should be developed. How can the maker movement use the tensions for its growth and make sure these tensions will not weaken the movement from the inside?

Author Contributions: Conceptualisation, H.S., M.Å. and J.M.; methodology, H.S. and M.Å.; analysis, H.S.; writing—original draft preparation, H.S., M.Å., B.K., J.M. and R.S.; writing-review and editing, M.A., H.S. and B.K. All authors have read and agreed to the published version of the manuscript.

Funding: This research was funded by the European Horizon 2020 Research Funding Programme, grant number 101006285.

Institutional Review Board Statement: Not applicable.

Informed Consent Statement: Not applicable.

Data Availability Statement: The data presented in this study are available in Critical Making Zotero library (https:/ / www.zotero.org/groups/3695948/critical_making_literature/library).

Acknowledgments: We would like to thank the whole Critical Making Consortium for their collaboration and the inspiring discussions contributing to this work.

Conflicts of Interest: The authors declare no conflict of interest.

\section{References}

1. Millard, J.; Sorivelle, M.N.; Deljanin, S.; Unterfrauner, E.; Voigt, C. Is the Maker Movement Contributing to Sustainability? Sustainability 2018, 10, 2212. [CrossRef]

2. Seo, J. Is the Maker Movement Inclusive of ANYONE? Three Accessibility Considerations to Invite Blind Makers to the Making World. TechTrends 2019, 63, 514-520. [CrossRef]

3. Johns, J.; Hall, S.M. 'I have so little time [ . . . ] I got shit I need to do': Critical perspectives on making and sharing in Manchester's FabLab. Environ. Plan. A Econ. Space 2020, 52, 1292-1312. [CrossRef]

4. Webb, H.; Nurse, J.R.C.; Bezuidenhout, L.; Jirotka, M. LabHackathons to Overcome Laboratory Equipment Shortages in Africa: Opportunities and Challenges. In Proceedings of the Chi Ea '19 Extended Abstracts: Extended Abstracts of the 2019 Chi Conference on Human Factors in Computing Systems, Glasgow, UK, 4-9 May 2019.

5. Hui, J.S.; Gerber, E.M. Developing makerspaces as sites of entrepreneurship. In Proceedings of the 2017 ACM Conference on Computer Supported Cooperative Work and Social Computing, Portland, OR, USA, 25 February-1 March 2017; pp. $2023-2038$.

6. Lindtner, S.; Bardzell, S.; Bardzell, J. Reconstituting the Utopian Vision of Making: HCI After Technosolutionism. In Proceedings of the 2016 CHI Conference on Human Factors in Computing Systems (CHI '16), New York, NY, USA, 7-12 May 2016; Association for Computing Machinery: New York, NY, USA; pp. 1390-1402.

7. Lindtner, S.; Lin, C. Making and its promises. CoDesign 2017, 13, 70-82. [CrossRef]

8. Smith, A.; Hargreaves, T.; Hielscher, S.; Martiskainen, M.; Seyfang, G. Making the most of community energies: Three perspectives on grassroots innovation. Environ. Plan. A Econ. Space 2016, 48, 407-432. [CrossRef]

9. Bogers, L.; Chiappini, L. The Critical Makers Reader; Amsterdam University of Applied Sciences: Amsterdam, The Netherlands, 2019.

10. The Makerbot Obituary. Available online: https://hackaday.com/2016/04/28/the-makerbot-obituary/ (accessed on 10 October 2021).

11. Whitaker, K.; Guest, O. \#bropenscience is broken science. Psychologist 2020, 33, 34-37.

12. Van Holm, E.J. Makerspaces and contributions to entrepreneurship. Procedia-Soc. Behav. Sci. 2015, 195, 24-31. [CrossRef]

13. Tanenbaum, J.G.; Williams, A.M.; Desjardins, A.; Tanenbaum, K. Democratizing technology: Pleasure, utility and expressiveness in DIY andmaker practice. In Proceedings of the SIGCHI Conference on Human Factors in Computing Systems (CHI '13), Paris, France, 27 April-2 May 2013; p. 2603.

14. Anderson, C. Makers: The New Industrial Revolution; Crown Publishing Group: New York, NY, USA, 2012. 
15. Ratto, M. Defining Critical Making. In Conversations in Critical Making; Hertz, G., Ed.; Blueshift Series; CTheory Books: Victoria, BC, Canada, 2015.

16. Ratto, M. Critical making: Conceptual and material studies in technology and social life. Inf. Soc. 2011, 27, 252-260. [CrossRef]

17. Hertz, G. (Ed.) Critical Making. 2012. Available online: http://www.conceptlab.com/criticalmaking/ (accessed on 3 December 2021).

18. Hertz, G. (Ed.) Disobedient Electronics: Protest; The Studio for Critical Making: Vancouver, BC, Canada, 2016.

19. Sipos, R.; Wenzelmann, V. Critical Making with an dfor Communities: Community-Driven Critical Making Grounded in Practitioners' Perspectives on Definition and Praxis. In Proceedings of the 10th International Conference on Communities \& Technologies-Wicked Problems in the Age of Tech (C\&T '21), Seattle, WA, USA, 20-25 June 2021; ACM: New York, NY, USA, 2021.

20. A Spiral of Openness. Available online: https:// opendott.org/posts/a-spiral-of-openness/ (accessed on 13 September 2021).

21. Torraco, R.J. Writing integrative literature reviews: Using the past and present to explore the future. Hum. Resour. Dev. Rev. 2016, 15, 404-428. [CrossRef]

22. Tranfield, D.; Denyer, D.; Smart, P. Towards a Methodology for Developing Evidence-Informed Management Knowledge by Means of Systematic Review. BJM 2003, 14, 207-222. [CrossRef]

23. Web of Science. Available online: https://clarivate.com/webofsciencegroup/solutions/web-of-science/ (accessed on 25 November 2021).

24. Rubow, E. Open Source Hardware. Technical Report 2008. pp. 1-5. Available online: https://cseweb.ucsd.edu/classes/fa08/ cse237a/topicresearch/erubow_tr_report.pdf (accessed on 3 December 2021).

25. Getting Started with Fab Labs. Available online: https:/ / fabfoundation.org/getting-started/ (accessed on 28 October 2021).

26. Kera, D. Hackerspaces and DIYbio in Asia: Connecting Science and Community with Open Data, Kits and Protocols. J. Peer Prod. 2012, 2, 1-8.

27. Browder, R.E.; Aldrich, H.E.; Bradley, S.W. The emergence of the maker movement: Implications for entrepreneurship research. J. Bus. Ventur. 2019, 34, 459-476. [CrossRef]

28. Aryan, V.; Bertling, J.; Liedtke, C. Topology, typology, and dynamics of commons-based peer production: On platforms, actors, and innovation in the maker movement. Creat. Innov. Manag. 2021, 30, 63-79. [CrossRef]

29. Langley, D.J.; Zirngiebl, M.; Sbeih, J.; Devoldere, B. Trajectories to reconcile sharing and commercialization in the maker movement. Bus. Horiz. 2017, 60, 783-794. [CrossRef]

30. Morreale, F.; Moro, G.; Chamberlain, A.; Benford, S.; McPherson, A.P. Building a Maker Community around an Open Hardware Platform. In Proceedings of the 2017 ACM SIGCHI Conference on Human Factors in Computing Systems (CHI'17), Denver, CO, USA, 6-11 May 2017; Assoc Computing Machinery: Denver, CO, USA, 2017; pp. 6948-6959.

31. Samuels, K. The Meanings in Making: Openness, Technology and Inclusive Music Practices for People with Disabilities. Leonardo Music J. 2015, 25, 25-29. [CrossRef]

32. Fonseca, F. Gambiarra: Repair Culture. In Leaving the Box: Entrepreneurship, Innovation and Initiatives; Ahnfelt, K.A., Donlin, P., Frænkel-Eids, J., Gleitsmann, D., Gresko, K.E., Hurníková, C., Lilleby, K., Svoren, M.O., Thompson, S.M., Eds.; Harvard Business Publishing: Harvard, MA, USA, 2015; pp. 54-63.

33. Meissner, J.L. Making with Disabilities, DIY Assistive Technology \& Participatory Challenges. Presented at the ACM CHI 2018 Workshop: Maker Movements, Do-It-Yourself Cultures and Participatory Design: Implications for HCI Research. Available online: https:/ / makersdiyparticipatorydesign.files.wordpress.com/2018/04/meissner.pdf (accessed on 23 August 2021).

34. Bosse, J.K.; Pelka, B. Peer production by persons with disabilities-opening 3D-printing aids to everybody in an inclusive MakerSpace. J. Enabling Technol. 2020, 14, 41-53. [CrossRef]

35. Sánchez-Criado, T.; Rodríguez-Giralt, I.; Mencaroni, A. Care in the (critical) making. Open prototyping, or the radicalisation of independent-living politics. ALTER Eur. J. Disabil. Res. 2016, 10, 24-39. [CrossRef]

36. Collins, J.T.; Knapper, J.; Stirling, J.; Mduda, J.; Mkindi, C.; Mayagaya, V.; Mwakajinga, G.A.; Nyakyi, P.T.; Sanga, V.L.; Carbery, D.; et al. Robotic microscopy for everyone: The OpenFlexure microscope. Biomed. Opt. Express 2020, 11, 2447-2460. [CrossRef] [PubMed]

37. Fernando, P. Tools for Public Participation in Science: Design and Dissemination of Open-Science Hardware. In Proceedings of the 2019 on Creativity and Cognition (C\&C'19), San Diego, CA, USA, 23-26 June 2019; pp. 697-701.

38. Haldrup, M.; Hobye, M.; Padfield, N. The bizarre bazaar: FabLabs as hybrid hubs. CoDesign 2018, 14, 329-344. [CrossRef]

39. Dandonoli, P. Open innovation as a new paradigm for global collaborations in health. Glob. Health 2013, 9, 1-5. [CrossRef]

40. Kieslinger, B.; Schaefer, T.; Fabian, C.M.; Biasin, E.; Bassi, E.; Freire, R.R.; Mowoh, N.; Arif, N.; Melis, P. COVID-19 Response from Global Makers: The Careables Cases of Global Design and Local Production. Front. Sociol. 2021, 6, 629587. [CrossRef]

41. Corsini, L.; Dammicco, V.; Moultrie, J. Frugal innovation in a crisis: The digital fabrication maker response to COVID-19. RD Manag. 2021, 51, 195-210. [CrossRef]

42. Pearce, J.M. Distributed manufacturing of open source medical hardware for pandemics. J. Manuf. Mater. Process. 2020, 4, 49. [CrossRef]

43. Taylor, N.; Hurley, U.; Connolly, P. Making community: The wider role of makerspaces in public life. In Proceedings of the 2016 CHI Conference on human factors in Computing systems, San Jose, CA, USA, 7-12 May 2016; pp. 1415-1425. 
44. Ahmadi, M.; Weibert, A.; Wenzelmann, V.; Aal, K.; Gäckle, K.; Wulf, V.; Marsden, N. Designing for openness in making: Lessons learned from a digital project week. In Proceedings of the 9th International Conference on Communities \& TechnologiesTransforming Communities, Vienna, Austria, 3-7 June 2019; pp. 160-171.

45. Taylor, J.L.; Vyas, D.; Sharp, T. Diversity and coherence in a hackerspace for people from a low socioeconomic community. In Proceedings of the 29th Australian Conference on Computer-Human Interaction, Brisbane, Australia, 28 November-1 December 2017; pp. 238-247.

46. Fasoli, A.; Tassinari, S. Engaged by design: The role of emerging collaborative infrastructures for social development. Roma makers as a case study. Des. J. 2017, 20 (Suppl. S1), S3121-S3133. [CrossRef]

47. Mahajan, S.; Luo, C.H.; Wu, D.Y.; Chen, L.J. From Do-It-Yourself (DIY) to Do-It-Together (DIT): Reflections on designing a citizen-driven air quality monitoring framework in Taiwan. Sustain. Cities Soc. 2021, 66, 102628. [CrossRef]

48. Vohland, K.; Land-Zandstra, A.; Ceccaroni, L.; Lemmens, R.; Perelló, J.; Ponti, M.; Samson, R.; Wagenknecht, K. The Science of Citizen Science; Springer Nature: Basingstoke, UK, 2021.

49. England, L.E. Managing making and makers in open-access craft studios: The case of Turning Earth. Soc. Enterp. J. 2020, 16, 159-177. [CrossRef]

50. Record, I.; Ratto, M.; Ratelle, A.; Ieraci, A.; Czegledy, N. DIY prosthetics workshops: 'Critical Making' for public understanding of human augmentation. In Proceedings of the 2013 IEEE International Symposium on Technology and Society (ISTAS): Social Implications of Wearable Computing and Augmediated Reality in Everyday Life, Toronto, ON, Canada, 27-29 June 2013; pp. 117-125.

51. Holroyd, A.T. From stitch to society: A multi-level and participatory approach to design research. Des. Issues 2017, 33, 11-24. [CrossRef]

52. Kirkpatrick, G. Technical Politics: Andrew Feenberg's Critical Theory of Technology; Manchester University Press: Manchester, UK, 2020.

53. Makov, T.; Fitzpatrick, C. Is repairability enough? Big data insights into smartphone obsolescence and consumer interest in repair. J. Clean. Prod. 2021, 313, 127561. [CrossRef]

54. Browne, K.; Swift, B.; Nurmikko-Fuller, T. Eating Computers Considered Harmful. In Proceedings of the Extended Abstracts of the 2020 CHI Conference on Human Factors in Computing Systems, Honolulu, HI, USA, 25-30 April 2020; pp. 1-13.

55. Riisgaard, H.; Mosgaard, M.; Zacho, K.O. Local circles in a circular economy: The case of smartphone repair in Denmark. Eur. J. Sustain. Dev. 2016, 5, 109-124.

56. Vyas, D.; Vines, J. Making at the Margins: Making in an Under-resourced e-Waste Recycling Center. In Proceedings of the ACM on Human-Computer Interaction, Glasgow, UK, 4-9 April 2019; pp. 1-23.

57. Irie, N.R.; Hsu, Y.C.; Ching, Y.H. Makerspaces in diverse places: A comparative analysis of distinctive national discourses surrounding the maker movement and education in four countries. TechTrends 2019, 63, 397-407. [CrossRef]

58. Diez, T. Personal fabrication: Fab labs as platforms for citizen-based innovation, from microcontrollers to cities. Nexus Netw. J. 2012, 14, 457-468. [CrossRef]

59. Turner, F. Millenarian tinkering: The puritan roots of the maker movement. Technol. Cult. 2018, 59, S160-S182. [CrossRef]

60. Ryana, T.; Striukova, L. Open social innovation dynamics and impact: Exploratory study of a fab lab network. RD Manag. 2019, 49, 383-395. [CrossRef]

61. Schor, J.B.; Fitzmaurice, C.; Carfagna, L.B.; Attwood-Charles, W.; Poteat, E.D. Paradoxes of openness and distinction in the sharing economy. Poetics 2016, 54, 66-81. [CrossRef]

62. Siu, A.F.; Kim, S.; Miele, J.A.; Follmer, S. shapeCAD: An accessible 3D modelling workflow for the blind and visually-impaired via 2.5 D shape displays. In Proceedings of the 21st International ACM SIGACCESS Conference on Computers and Accessibility, Pittsburgh, PA, USA, 28-30 October 2019; pp. 342-354.

63. Bergman, B.J., Jr.; McMullen, J.S. Entrepreneurs in the making: Six decisions for fostering entrepreneurship through maker spaces. Bus. Horiz. 2020, 63, 811-824. [CrossRef]

64. Giusti, J.D.; Alberti, F.G.; Belfanti, F. Makers and clusters. Knowledge leaks in open innovation networks. J. Innov. Knowl. 2020, 5, 20-28. [CrossRef]

65. Troxler, P.; Wolf, P. Digital maker-entrepreneurs in open design: What activities make up their business model? Bus. Horiz. 2017, 60, 807-817. [CrossRef]

66. Powell, A. Democratizing production through open source knowledge: From open software to open hardware. Media Cult. Soc. 2012, 34, 691-708. [CrossRef]

67. Ferreira, E. Open Hardware Business Models; Open Source Business Resource. 2008. Available online: https://www.timreview. $\mathrm{ca} /$ article/136 (accessed on 3 December 2021).

68. Hamidi, F.; Owuor, P.; Onyango, D.; Hynie, M.; Mcgrath, S.; Baljko, M. Participatory design of DIY digital assistive technology in Western Kenya. In Proceedings of the Second African Conference for Human Computer Interaction: Thriving Communities AfriCHI '18, Windhoek, Namibia, 3-7 December 2018; pp. 1-11.

69. Dreessen, K.; Schepers, S.; Leen, D. From Hacking Things to Making Things. Rethinking making by supporting non-expert users in a FabLab. IxDEA 2016, 30, 47-64.

70. Frank, D.Z.; Douglas, E.P.; Williams, D.N.; Crane, C.D. Investigating Culturally-Contextualized Making with the Navajo Nation: Broadening the Normative Making Mentality. Eng. Stud. 2020, 12, 177-194. [CrossRef] 
71. Dufva, M.; Ikäheimo, H.; Dufva, T. Grasping the Tensions Affecting the Futures of Internet. J. Futures Stud. 2020, $24,51-60$.

72. Godhe, A.-L.; Lilja, P.; Selwyn, N. Making sense of making: Critical issues in the integration of maker education into schools. Tehcnol. Pedagog. Educ. 2019, 28, 317-328. [CrossRef]

73. Miles, I.; Keenan, M.; Kaivo-oja, J. Handbook of Knowledge Society Foresight; European Foundation for the Improvement of Living and Working Conditions: Dublin, Ireland, 2003. 